\title{
Cutaneous Melanoma Clinical TNM Finding v6
}

National Cancer Institute

\section{Source}

National Cancer Institute. Cutaneous Melanoma Clinical TNM Finding v6. NCI Thesaurus. Code 448896.

A clinical finding about one or more characteristics of cutaneous melanoma, following the rules of the TNM AJCC v6 classification system. TNM clinical findings are based on information obtained prior to the first definitive treatment through physical examination, diagnostic imaging, endoscopy, biopsy or laboratory testing. 